\section{ӘDӘBIYYYAT \\ İCMALI}

\section{ОБЗОР}

ЛИТЕРАТУРЫ
LITERATURE

REVIEW

\title{
РОЛЬ ПАТОГЕНЕТИЧЕСКИХ МЕХАНИЗМОВ \\ В ФОРМИРОВАНИИ ПАТОЛОГИИ ЦЕНТРАЛЬНОЙ НЕРВНОЙ СИСТЕМЫ ПЕРИНАТАЛЬНОГО ПЕРИОДА У НЕДОНОШЕННЫХ ДЕТЕЙ
}

\author{
*Асадова Т.A. \\ Азербайджанский Государственный Институт Усовершенствования врачей им. А. Алиева, кафедра \\ педиатрии, Баку, Азербайджан
}

В статье рассматриваются патогенетические механизмы формирования патологии перинатального периода, их роль в возникновении как гипоксических, так и воспалительных процессов у недоношенных детей. Согласно данным литературы за последние годы, головной мозг недоношенного ребенка не является совершенной системой защиты от возникновения гипоксических и воспалительных процессов. В статье приведены характерные особенности строения головного мозга недоношенных детей в зависимости от гестационного возраста, в сравнении с доношенными. Считается, что инфекционные и неинфекционные патологические процессы, происходящие в фетоплацентарной системе, непосредственно влияют на эмбриональное развитие плода, в результате чего, патологическому воздействию чаще всего подвержен головной мозг.

Ключевые слова: перинатальная патология, центральная нервная система, преждевременные роды, недоношенные дети, гипоксические поражения центральной нервной системы.

$\bar{\Pi}$ реждевременное рождение ребенка является как важной медицинской, так и социальной проблемой современного общества, на долю которого приходится 12\% от всех живорожденных [24]. В структуре детской смертности недоношенных детей показатель смертности напрямую связан и зависим от региональной неонатальной помощи в разных регионах мира [24]. Статистические исследования показывают, что даже в развитых странах мира частота возникновения преждевременных родов увеличилась с 9-9,4\% до 12,7-14\% по сравнению с 80-ми годами прошлого века $[13,52]$. Статистические данные также свидетельствуют, что каждый год во всем мире из 500000 преждевременных родов 75\% приходится на 34-36 недель беременности, а оставшиеся 25\% характерны для более низкого гестационного возраста $[9,16,29]$. Проведенные исследования показали, что $50 \%$ всех случаев преждевременных родов происходят спонтанно, без видимой причины, 40\% по медицинским показаниям, $10 \%$ случаев - в результате преждевременной отслойки плаценты [12]. Безусловно, преждевременное рождение ребенка является результатом воздействия не одного, а целого комплекса тератогенных факторов. Преждевременные роды связаны не только с рождением ребенка с низкой массой тела в результате морфофункциональной незрелости его организма и гестационным возрастом, но и с патологическими состояниями, тре*e-mail: tarana.asadova.67@mail.ru бующими квалифицированной и высококачественной медицинской помощи, так как у этих детей в более позднем возрасте наблюдается высокий риск развития как метаболических, кардиоваскулярных, онкологических заболеваний, так и развитие умственной отсталости, психоневрологических осложнений и т.д. $[6,7,10$, $28,46]$. Ранние и поздние осложнения преждевременных родов в основном зависят от внутриутробного состояния развития плода и периода гестации, в течение которого завершается беременность $[10,28,46]$.

В последние годы, среди причин инвалидности у недоношенных детей, перинатальное поражение ЦНС занимает одно из первых мест, к которым относятся: детский церебральный паралич (ДЦП), встречающийся с частотой $60 \%$ случаев, врожденная окклюзионная гидроцефалия - 7,4\% случаев, ретинопатия, в последствии приводящее к развитию слепоты у ребенка [1, 36]. Необходимо отметить, что в последние годы во всех странах мира отмечается неуклонный рост частоты ретинопатии у недоношенных с очень низкой и экстремально низкой массой тела при рождении, что является предметом дискуссии ученых многих стран [1].

Из-за более серьезного прогрессирования и формирования осложнений перинатальных патологий, новорожденные с синдромом задержки фетального развития составляют наиболее высокую группу риска $[32,42]$. Примерно 50-70\% этих детей после рождения 
получают длительное лечение в отделении интенсивной терапии новорожденных. Кроме того, 70\% из них сталкиваются с проблемами поведения и памяти в более позднем возрасте $[15,50]$. Среди детей, включенных в группу риска развития и поведенческих отклонений, наибольшую группу составляют дети с экстремально низкой массой тела. Считается, что основные проблемы, с которыми сталкиваются эти дети в неонатальном периоде, связаны с питанием и инфекцией $[19,20]$. Не только восполнение энергетических потребностей в необходимых питательных веществах, но и применение пероральных, а также введение парентеральных микронутриентов предотвращают возникновение ряда психосоциальных проблем в более позднем возрасте [19, 20, 31].

Одним из факторов, приводящих к нарушению раннего адаптационного периода у недоношенных детей, является отсутствие ответной реакции на болевое раздражение. Считается, что чем меныше гестационный возраст и выраженная морфофункциональная незрелость недоношенных детей, тем вероятнее формирование кумулятивной реакции организма в ответ на болевое раздражение, которое впоследствии может привести не только к дисфункциональным изменениям поведенческих расстройств, но и всех органов и систем $[26,30,44]$.

Исследования, в частности, проведенные автором Брыксиной Е.Ю. показали, что к повреждающему действию хронической внутриутробной гипоксии и острой интранатальной асфиксии наиболее подвержены геста- ционно незрелые дети, вследствие морфофункциональной незрелости головного мозга, нарушения цереброваскулярной ауторегуляции, снижения активности антиоксидантной систем, особенностей метаболических процессов, энергетического дефицита и низкого уровня пластических процессов [2, 21]. Согласно данным автора, частота перинатальных поражений составляет $65-85 \%$ [2, 21].

Во время беременности, в результате любого тератогенного воздействия на организм, может формироваться воспалительный процесс, который сопровождается плацентарной дисфункцией. И в зависимости от активации фагоцитарной системы и тяжести воспалительного процесса, в фетоплацентарную систему продуцируются различные биологические и вазоактивные агенты, а также воспалительные медиаторы. Исследования последних лет выявили, что в зависимости от периода беременности, наблюдаются отличительные результаты концентраций фагоцитарных и васкулярных медиаторов от утероплацентарной системы, которое указывает на то, что плод подвергается более серьезным воздействиям при рождении.

Существует корреляционная связь между дисфункцией мозга у новорожденных детей с повышенными концентрациями IL-6 и TNF- $\alpha$ в амниотической жидкости и пуповинной крови $[27,33,49,51]$. Это показывает, что реакция плода на фетальное воспаление является одним из вредных факторов для центральной нервной системы, включая различные органы и системы $[49,51]$.

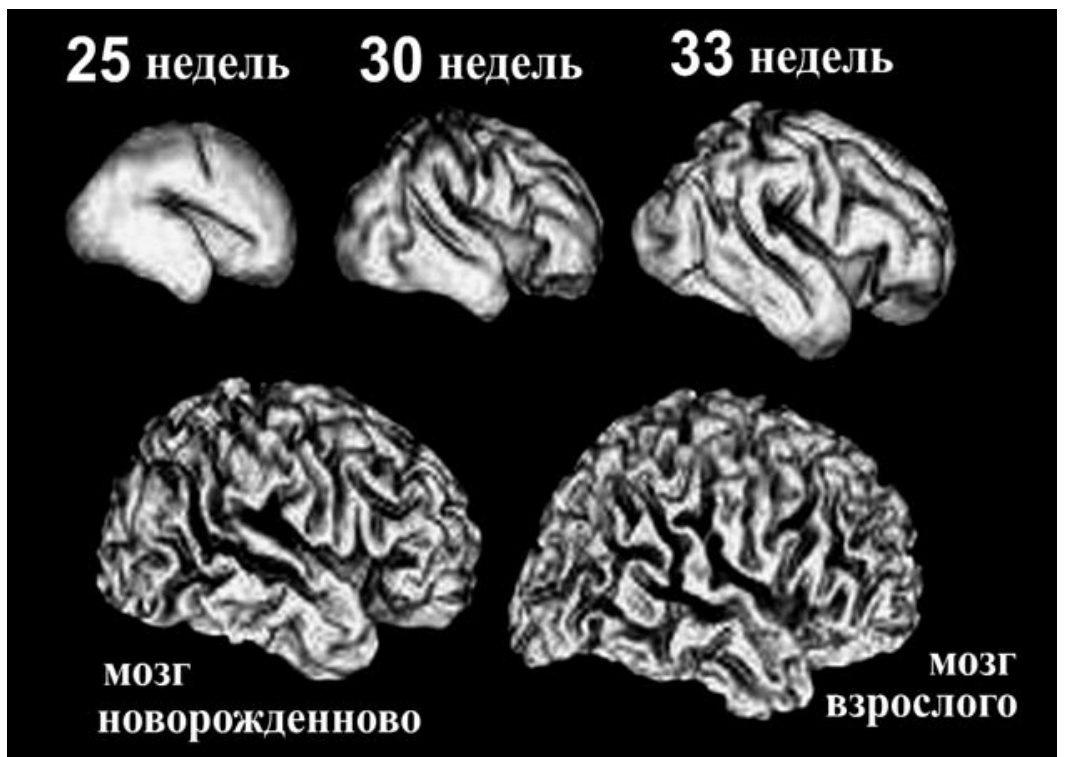

Рис. 1. Развитие головного мозга ребенка по неделям (верхний ряд); в нижнем ряду показано строение головного мозга новорожденного и взрослого в сравнении ([http://www.health-newsblog.com/blogs/permalinks/8-2006/abnormal-cortical-development-after-premature-birth.html) 
В результате инфекционных и неинфекционных патологических процессов, происходящих в фетоплацентарной системе, непосредственно влияющих на эмбриональное развитие плода, патологическому воздействию чаще всего подвержен головной мозг. Нервная ткань и нервные клетки в целом защищены гематоэнцефальным барьером от разрушительного эффекта медиаторов, циркулирующих в общем кровообращении во время воспалительных процессов. Жестко структурированный гематоэнцефальный барьер не проницаем даже для малых молекул. Но считается, что головной мозг не может всегда быть совершенной системой защиты от воспалительных процессов. Если сделать короткий экскурс в анатомию, то можно привести характерные особенности строения головного мозга недоношенных детей (рис. 1-4), в сравнительном аспекте с данным органом доношенного ребенка. На рис. 1 показано развитие головного мозга ребенка по неделям.

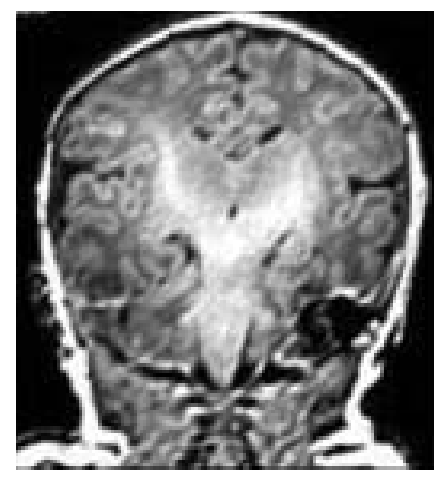

a

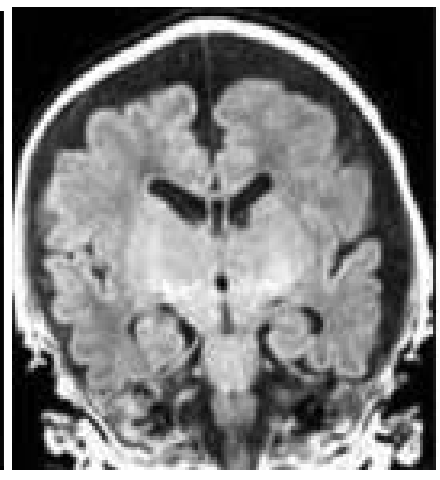

6
Рис. 2. (а) МРТ головного мозга доношенного ребенка (б) МРТ головного мозга недоношенного ребенка ([http://www.health-news-blog.com/blogs/ permalinks/8-2006/abnormal-cortical-development-afterpremature-birth.html)

На рис. 2 (а; б) представлена МРТ исследования головного мозга недоношенного ребенка в сравнении с головным мозгом доношенного ребенка.

Таким образом, для головного мозга недоношенного ребенка характерно во-первых: малое количество извилин и борозд, вентрикуломегалия, во-вторых: наличие герминального матрикса, широкое субарахноидальное пространство. Доказано, что нервная трубка закладывается на первых неделях внутриутробного развития, но несмотря на это, сам мозг своего развития достигает значительно позже после рождения.

Очень важно подчеркнуть, что для недоношенных детей физиологически характерно вентрикуломегалия, широкое субарахноидальное пространство, что было вышеизложено, к сожалею, имеет место гипердиагностика и очень часто в клинической практике принимают за гидроцефалию внутреннюю или наружную, назначая длительный прием лекарственных средств, которые в итоге оказываются неэффективными, не давая положительный результат.

Имеются исследования, которые с помощью МРТ выявили и показали, что объем головного мозга отстает в развитии. На рис.3 показано отставание в развитии объема головного мозга от роста коры после рождения недоношенного младенца, а также показана зависимость наличия неврологических нарушений от диспропорции коры к объему. Необходимо отметить, что в исследование были включены здоровые недоношенные дети без внутричерепных кровоизлияний. На рис. 3 МРТ показан рост паренхимы головного мозга недоношенных детей в третий триместр беременности, на фоне отсутствия мозговой/мозжечковой травмы.

На рис. 4 в верхнем ряду представлен головной мозг недоношенного ребенка, в нижнем - эмбриональный.

На рис 4 представлены анатомические изображения недоношенного ребенка с гестационным сроком 31 недель (верхний ряд) и внутриутробного плода с гестационным сроком в 32 недели (нижний ряд).

На данном рисунке показаны: темно-серый цвет представляет головной мозг; серый цвет - промежуточный; светло-серый - мозжечок, ствол мозга и белый спинномозговая жидкость [14]. Так, некоторые участки, окружающие ткани желудочков головного мозга лишены гематоэнцефалитического барьера и в этих зонах крупные молекулы пептидов, цитокинов, вирусов и бактериальных токсинов могут легко вступать в контакт с элементами нервной клетки ЦНС [36].

На рис.5 показана схема отражающая открытие гемиканалов астроцита при хроническом воспалительном процессе головного мозга до начальной травмы. Inflammasomes относятся к врожденной иммунной системе, который регулирует активацию каспазы 1 и воспалительный процесс в нейроглие. Гемиканалы Connexin осуществляют приток внутриклеточного $\mathrm{Ca}^{2+}$, а также выход АТФ во внеклеточное пространство.

Также на рисунке показано нарушение целостности гематоэнцефалитического барьера за счет процессов, связанных с NLRP3: NOD-like рецептор протеин-3; ASC: адаптированный протеин; про IL-1 и IL-1 $\beta[17,22]$.

Существует корреляционная связь между дисфунк- 


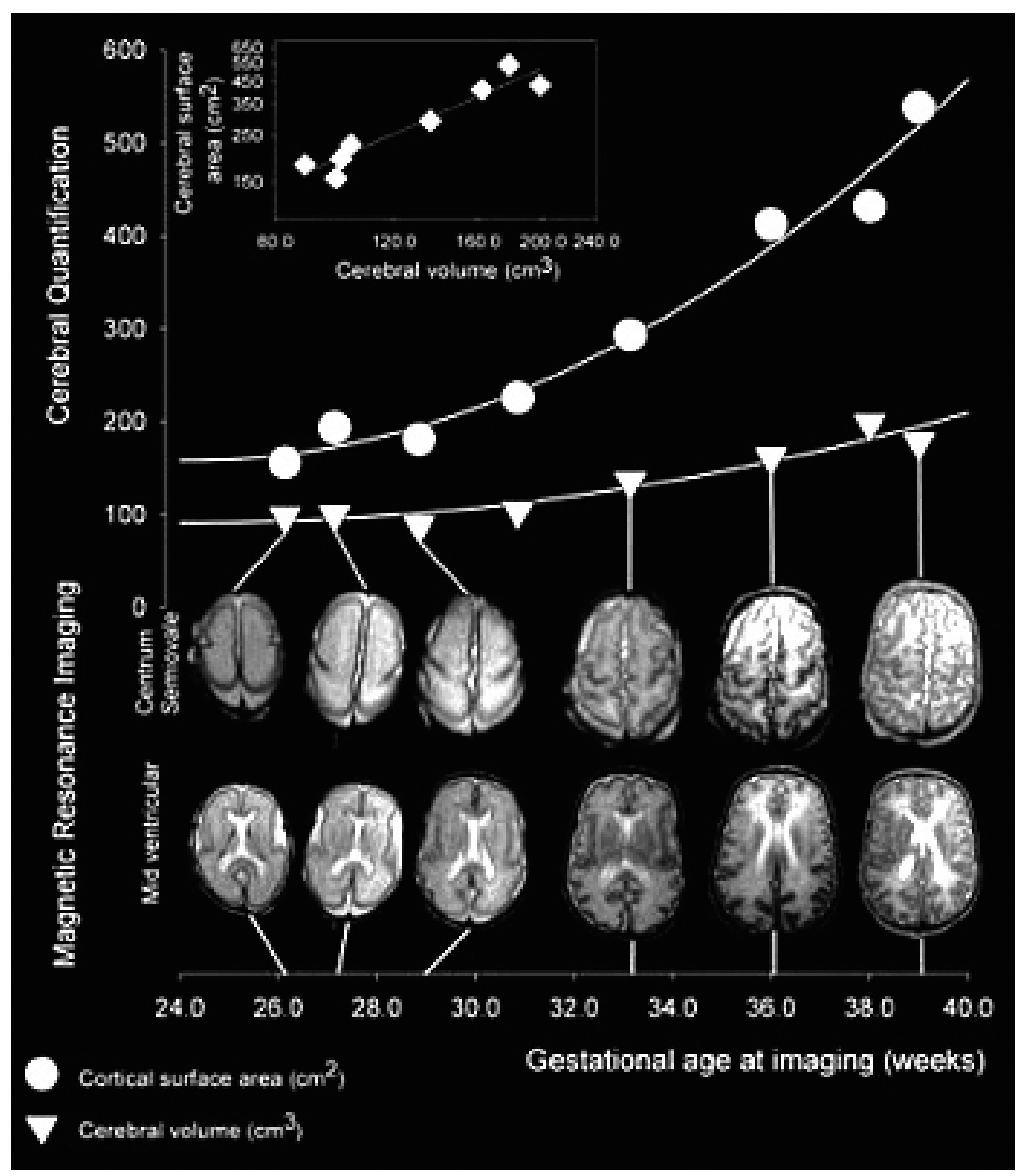

Рис. 3. Развитие головного мозга ребенка в зависимости от гестационного возраста ([http://www.health-news-blog.com/blogs/permalinks/8-2006/abnormal-cortical-development-after-premature-birth.html]) Примечание - - поверхность коры; $\nabla$ - объем вещества головного мозга; шкала $\mathrm{X}$ - гестационный возраст ребенка.

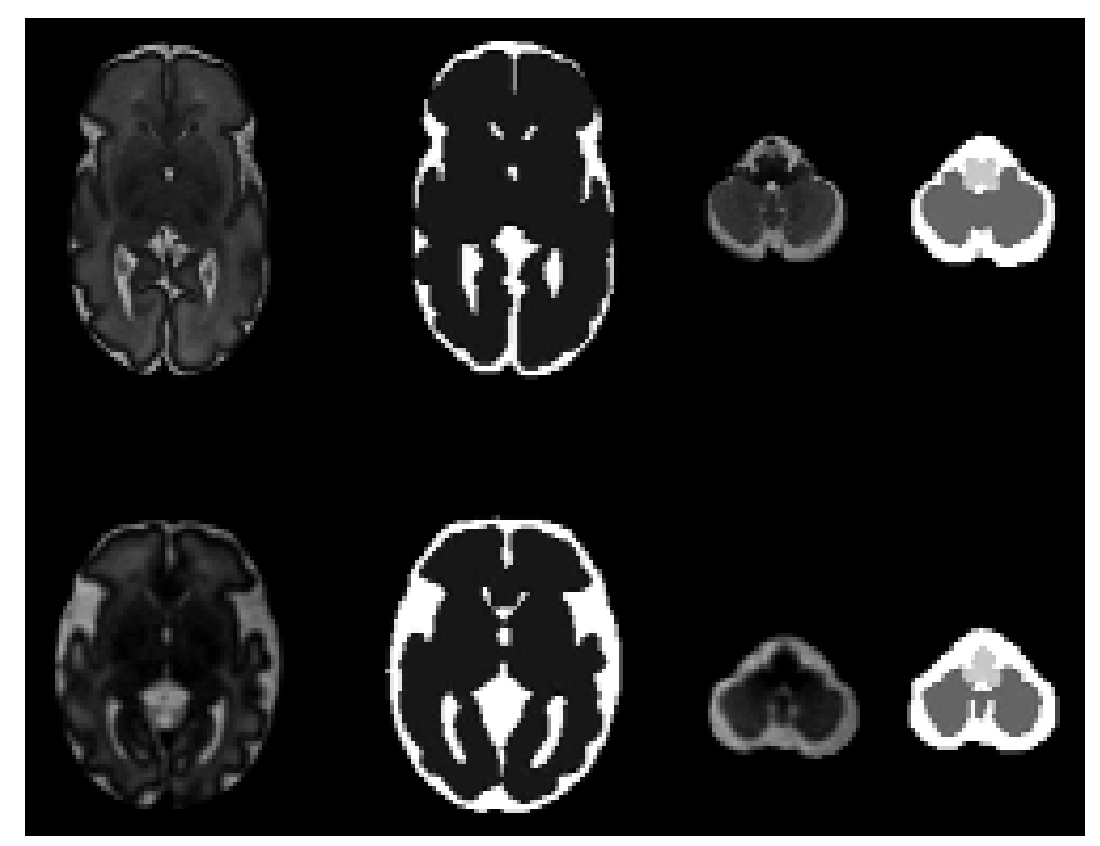

Рис. 4. МРТ головного мозга недоношенных детей ([Bouyssi-Kobar M., du Plessis A.J., McCarter R. et al. Third Trimester Brain Growth in Preterm Infants Compared With In Utero Healthy Fetuses // J. Pediatrics. American Academy of Pediatrics. 2016 Nov; vol. 138(5), p. 1640- 1646]) 
цией белого вещества головного мозга у новорожденных детей и повышенными концентрациями IL6 и TNF- $\alpha$ в амниотической жидкости и в пуповинной крови $[37,38]$. Это свидетельствует о том, что ответная реакция со стороны различных органов и систем плода на воспалительный процесс является одним из тератогенных факторов воздействия на ЦНС [37]. Другие исследования показывает, что медиаторы активация лейкоцитов являются фактором риска преждевременных родов $[18,22]$. Авторы также утверждают, что показатель IL-8 связан с неонатальным церебральным инсультом. Много споров и дискуссий, вокруг полученных результатов научных исследований к вопросу о том, являются ли органические повреждения головного мозга ответной реакцией на воспалительный процесс [39-43, 45, 48]. Многочисленные исследования связывают преждевременные роды с внутриутробными мунными реакциями плода или новорожденного оказывает существенное влияние на патологический процесс и возникновение ряда патологических состояний у детей различного гестационного возраста $[11,13,23-$ 25].

При остром и продолжительном течении церебральной ишемии, а также при вовлечении других патологических факторов (инфекция, наследственные факторы, экологические и т.д.), вслед за первичным повреждением, формируется вторичное повреждение клеток, что во многих случаях, в последующем приводит к более серьезным неврологическим повреждениям, имеющих органический характер, а также соматической дезадаптации. Одной из основных причин вторичного нейронального повреждения является нарушение функционального баланса пробуждения и торможения нейротрансмиттеров. В

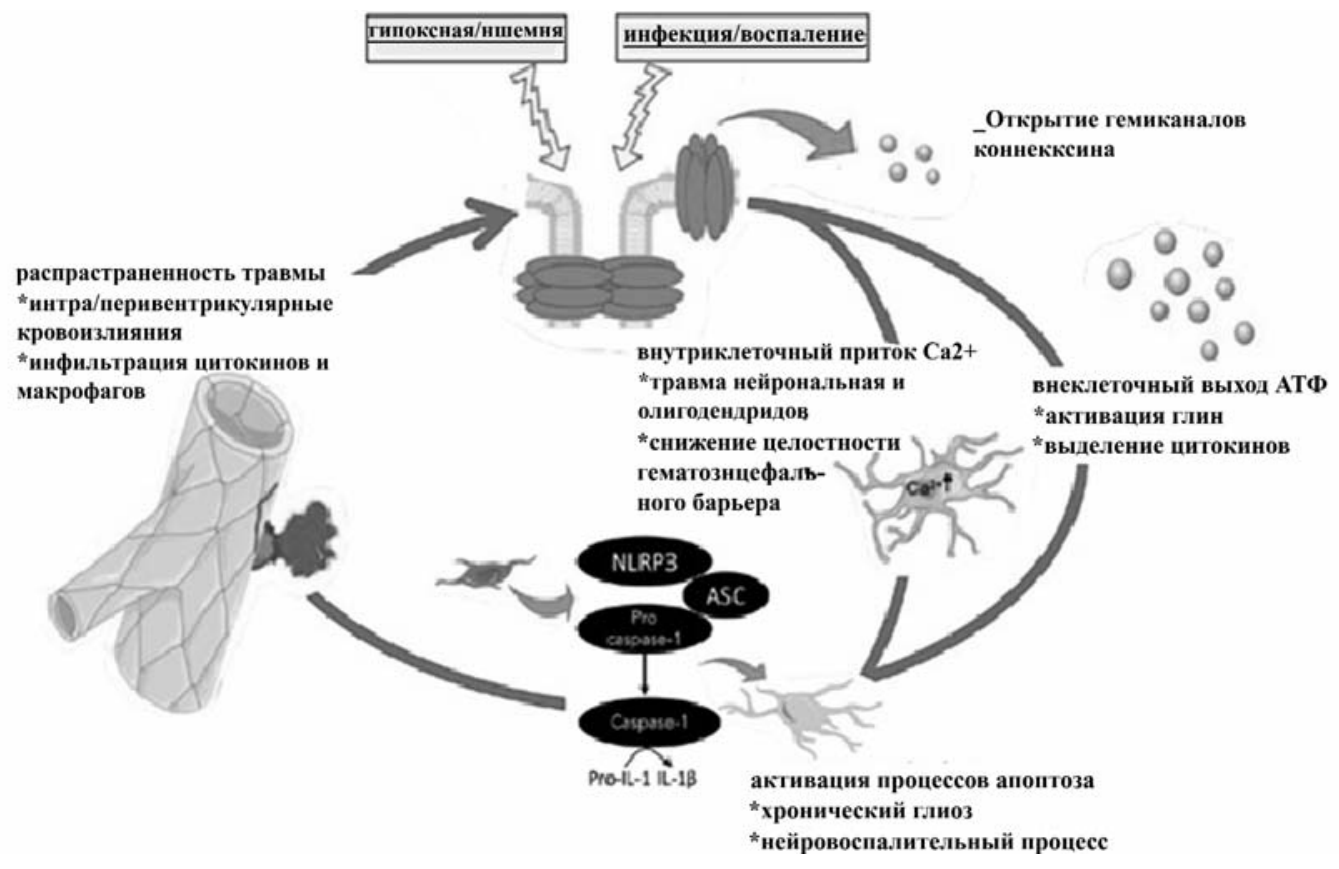

Рис. 5. Схема роли гемиканалов астроцита при хроническом воспалительном процессе головного мозга /Galinsky R., Davidson J.O., Dean J.M., Green C.R. et al. Glia and hemichannels: key mediators of perinatal encephalopathy // J.Neural Regen Res. 2018 Feb; vol. 13(2), p. 181-189]

инфекциями и хориоамнионитом [22, 34, 48]. Исследования показывают, что высокий уровень цитокинов вызывают преждевременные роды при беременности, гестационный срок которой менее 32 недель [33-35].

Таким образом, эндотелиальная дисфункция является основным фактором, стимулирующий внутриклеточную и сосудистую адгезию, что в итоге и приводит к активации клеток крови у плода $[8,11,35]$. Взаимосвязь между врожденными и адаптивными им- этом случае, повторное увеличение синтеза глутамата приводит к эпилептической активации в нейронах, нарушению энергетического баланса, и в итоге, к разрушению клетки $[43,47]$. Следующей причиной вторичного нейронального повреждения является развитие клеточного целлюлярного отека. Несмотря на то, что компесаторно, за счет ускорения мозгового кровообращения, в нервных клетках энергетические реакции восстанавливаются, но в 
других случаях, данный процесс носит временный характер и как итог, вторично формирует внутриклеточный отек. В образовании целлюлярного отека наряду с глутаматом участвуют свободные радикалы кислорода, что способствует формированию сложных каскадных реакций воспалительного характера.

\section{ЛИТЕРАТУРА - ӘDӘВIYYАТ - REFERENCES}

1. Альперина О.Н. Клинические особенности и методы патогенетической коррекции перинатального поражения центральной нервной системы у недоношенных детей с ретинопатией / Автореф. диссер ... на соиск. уч. ст. к.м.н. 2011, Екатеринбург, 21 с.

2 Брыскина Е.Ю. Патогенетические аспекты перинатальных поражений центральной нервной системы недоношенных детей // Ж.Вестник ТГУ. 2013, т.18, вып. 6, с. 3312-3314 3. Ковальчук-Ковалевская О.В. Особенности формирования функций ЦНС у новорожденных детей с задержкой внутриутробного развития / Автореф. диссер. ... на соиск. уч. ст. к.м.н., 2005, Санкт-Петербург, 22 с.

4. Михалев Е.В. Клинико-патогенетические аспекты гнойного менингита у недоношенных новорожденных с гипоксическим поражением центральной неврной системы / Автореф. диссер. ... на соиск. уч. ст. Д.м.н., 2005, Томск, 32 с.

5 Михалев Е.В., Кривоногова Т.С., Бабченко Е.Г. а соавт. Перинатальные поражения центральной нервной системы в структуре заболеваемости новорожденных детей г. Томска // Ж. Мать и дитя. 2011, №4 (47), с. 40-42.

6 Пальчик А.Б. Лекция по неврологии развития / Москва: МЕДпресс-информ, 2012, 368 с.

7. Пальчик А.Б., Федорова Л.А., Понятишин А.Е. Неврология недоношенных детей / Москва: МЕДпресс-информ, 2011, 352 c.

8. Adam Bitner, Sobala W., Kalinka J. Association Between Maternal and Fetal TLR4 (896A>G, 1196C > T) Gene Polymorphisms and the Risk of Pre-term Birth in the Polish Population // American Journal of Reproductive Immunology. 2013, vol. 69 , issue 3, p. 272-280

9. Althabe F., Belizan J.M., McClure E.M., HemingwayFoday J. et al. A population-based, multifaceted strategy to implement antenatal corticosteroid treatment versus standard care for the reduction of neonatal mortality due to preterm birth in low-income and middle-income countries: the ACT cluster-randomised trial // J.Lancet. 2015; vol.385(9968), p.629-639

10 Amy E. Doss, Melissa S. Mancuso, Suzanne P. Cliver et al. Gestational age at delivery and perinatal outcomes of twin gestations // J. AJOG. 2012, vol. 207, Issue 5, p. 410-406

11. Baburamani A.A., Hurling C., Stolp H. et. al. Mitoxondrial Optic Atrophy (OPA) 1 Pracessing is Altered in Response to Neonatal Hypoxic-Ishemic Brain Injury // Int. J. Molek. Science. 2015, vol. 16(9), p. 22509-22526

12. Black R.E., Cousens S., Johnson H.L. Lawn J.E. et al. Global, regional, and national causes of child mortality in 2008: a systematic analysis // J. Lancet, 2010, vol.375(9730), p.1969-1987 13. Blencowe H., Cousens S., Oestergaard M. et al. National, regional and worldwide estimates of preterm birth // J. The Lancet, June 2012, 9; vol.379(9832), p.2162-2172
Таким образом, несмотря на интенсивные исследования, проблема перинатального поражения головного мозга на сегодняшний день продолжает оставаться актуальной, что связано с высоким удельным весом этой патологии в структуре неврологической заболеваемости и смертности у детей.

14. Bouyssi-Kobar M., du Plessis A.J., McCarter R. et al. Third Trimester Brain Growth in Preterm Infants Compared With In Utero Healthy Fetuses // J. Pediatrics. American Academy of Pediatrics. 2016, vol. 138(5), p. 1640- 1646

15. Catov J.M., Nohr E.A., Olsen J., Ness R.B. Chronic hypertension related to risk for preterm and term small for gestational age births // J. Obstet. Gynecol., vol. 112, p. 290-296

16. Conde-Agudelo A., Diaz-Rossello J.L. Kangaroo mother care to reduce morbidity and mortality in low birthweight infants // Cochrane Database Syst Rev, 2014, vol. 4, CD002771 17. Davidson J.O., Drury P.P., Green C.R. et al. Connexin Hemichannel Blockade Is Neuroprotective after Asphyxia in Preterm Fetal Sheep // J. Plos One. 2014, vol. 9(5), p. 965-958 18. DiGiulio D.B., Gervasi M.T., Romero R., Vaisbuch E. et al. Microbial invasion of the amniotic cavity in pregnancies with small-for-gestational-age fetuses // J. Perinat. Med., 2010, vol. 38, p. 495-502

19. Eichenwald E.C., Stark Ann R. Management and Outcomes of Very Low Birth Weight // The New England journal of medicine. 2008, vol.358(16), p. 1701-1711

20. Finer N. To intubate or not - that is the question: continuous positive airway pressure versus surfactant and extremely low birthweight infants // J. Arch Dis. Child Fetal Neonatal Ed. 2006; vol.91, p. 392-394

21. Gaillard R., Steegers E.A.P., Tiemeier H. et al. Placental Vascular Dysfunction, Fetal and Childhood Growth, and Cardiovascular Development // J. Circulation, 2013, vol. 128, p. 2202-2210

22. Galinsky R., Davidson J.O., Dean J.M., Green C.R. et al. Glia and hemichannels: key mediators of perinatal encephalopathy // J. Neural Regen Res. 2018, vol. 13(2), p. 181-189

23. Gokina N.I., Kuzina O.Y., Vance A.M. Augmented EDHF signaling in rat uteroplacental vasculature during late pregnancy // Am. J. Physiol. Heart Circ Physiol., 2010, vol. 299, p. 1642-1652 24. Goldenberg R.L., Culhane J.F, Iams J.D, Romero R. Epidemiology and causes of preterm birth // The Lancet, 2008, vol.371, № 9606, p. 75-84

25. Hajek, Z., Germanova A., Koucky M., Zima T., Kopecky P. et al. 384 Detection of feto-maternal infection/inflammation by the soluble receptor for 385 advanced glycation end products (sRAGE): results of a pilot study // J. Perinat. Med. 2008, vol. 386 (5), p. 399-404

26. Holsti L., Grunau R.E., Shany E. Assessing pain in preterm infants in the neonatal intensive care unit: moving to a 'brainoriented' approach // J. Pain Manag., 2011, vol. 1(2), p. 171-179 27. Kadhim H.J., Duchateau J., Sebire G. Cytokines and brain injury: invited review // J. Intensive Care Med. 2008, vol. 23 p.236-249

28. Katz J., Lee A.C., Kozuki N., Lawn J.E., Cousens S. et al. 
Mortality risk in preterm and small-for-gestational-age infants in low-income and middle-income countries: a pooled country analysis // The Lancet, 2013, vol. 382, p. 417-425

29. Kinney M.V., Lawn J.E., Howson C.P. et al. 15 Million preterm births annually: what has changed this year? // J. Reprod. Health. 2012, vol. 9, p.28

30. Kistka Z.A., Palomar L., Lee K.A., Boslaugh S.E. et al. Racial disparity in the frequency of recurrence of preterm birth // Am. J. Obstet. Gynecol. 2007, vol. 196(2), p.131-136

31. Koo W.W., Hockman E.M. Posthospital discharge feeding for preterm infants: effects of standard compared with enriched milk formula on growth, bone mass, and body composition // American Journal of Clinical Nutrition. 2006, vol. 84, p.1357-1364

32. Lee A.C., Katz J., Blencowe H., Cousens S., Kozuki N. et al. National and regional estimates of term and preterm babies born small for gestational age in 138 low-income and middleincome countries in 2010 // J. The Lancet Global Health. 2013, vol. 1, p.26-36

33. Lee J., Romero R., Xu Y., Kim J.S., Park J.Y. et al. Maternal HLA panel-reactive antibodies in early gestation positively correlate with chronic chorioamnionitis: evidence in support of the chronic nature of maternal anti-fetal rejection // Am. J. Reprod. Immunol., 2011, vol. 66(6), p. 510-526

34. Lee J., Romero R., Xu Y., Kim J.S., Topping V. et al. A signature of maternal anti-fetal rejection in spontaneous preterm birth: chronic chorioamnionitis, anti-human leukocyte antigen antibodies, and C4d // J. Plos One. 2011, vol. 6(2), p.168-176. 35. Lee Y.H., Shynlova O., Lye S.J. Stretchinduced human myometrial cytokines enhance immune cell recruitment via endothelial activation. // J. Cell Mol. Immunol. 2015, vol.12, p. 231-242

36. Liu L., Johnson H.L., Cousens S., Perin J. et al. Global, regional, and national causes of child mortality: an updated systematic analysis for 2010 with time trends since $2000 / / \mathrm{J}$. Lancet, 2012, vol. 379, p.2151-2161

37. Mathews T.J., MacDorman M.F. Infant mortality statistics from the 2006 period linked birth/infant death data set. // J. Natl. Vital Stat. Rep., 2010, vol. 58(17), p.1-32

38. Menon R., Fortunato S.J., Edwards D.R., Williams S.M. Association of qenetic variants, ethnicity and preterm birth with amniotic fluid cytokine concentrations // J. Ann. Hum. Genet., 2010, vol. 74(2), p. 165-183

39. Mullany LC et al. Breast-feeding patterns, time to initiation, and mortality risk among newborns in southern Nepal // Journal of Nutrition. 2008, vol. 138, p.599-603
40. Muraskas J.K., Kelly A.F., Nash M.S, Goodman J.R. et al. The role of fetal inflammatory response syndrome and fetal anemia in nonpreventable term neonatal encephalopathy // Journal of Perinatology. 2016, doi:10.1038/jp. 2015.214

41. Neergard Lauran. Bed Rest During Pregnancy May Worsen Risk For Premature Birth / Associated Press. Retrieved. 2013, http://www huffingtonpost.com/2013/05/14/bed-rest-premature-birth_n_3272355. html

42. Qiu X., Lodha A., Shah P.S., Sankaran K., Seshia M.M. et al. Neonatal outcomes of small for gestational age preterm infants in Canada // Am. J. Perinatol. 2012, vol. 29, p. 87-94

43. Queenan J.T., Spong C.Y., Lockwood C.J. Protocols for HighRisk Pregnancies: An Evidence-Based Approach, 10 apr. 2015 44. Reddy U.M, Ko C.W., Raju T. NK., Willinger M. Delivery Indications at Late-Preterm Gestations and Infant Mortality Rates in the United States // J. Pediatrics, 2009, vol. 124, p. 234-240

45. Rinaldi S.F., Catalano R.D., Wade J. et al. Decidual neutrophil infiltration is not required for preterm birth in a mouse model of infection-induced preterm labor // J. Immunol., 2014, vol. 192, p.2315-2325

46. Risnes K.R., Vatten L.J., Baker J.L., Jameson K. et al. Birthweight and mortality in adulthood: a systematic review and meta-analysis // Int. J. Epidemiol., 2011, vol. 40, p. 647-661 47. Rubens C.E., Sadovsky Y., Muglia L., Gravett M.G. et al. Prevention of preterm birth: Harnessing science to address the global epidemic // J. Sci. Transl. Med., 2014, vol. 6, p. 262-265 48. Sanchez L., Prada C.E., Riaño-Medina C.E. et al. Endothelial dysfunction and preeclampsia: Role of oxidative stress // J. Frontiers in Physiology. 2014, vol.5, p. 372-376

49. Siwetz M., Blaschitz A., El-Heliebi A., Hiden U. et al. TNF- $\alpha$ alters the inflammatory secretion profile of human first trimester placenta // J. Laboratory Investigation, 2016, vol. 96, p. $428-438$

50. Souza J.P., Gulmezoglu A.M., Vogel J., Carroli G., Lumbiganon P. et al. Moving beyond essential interventions for reduction of maternal mortality (the WHO Multicountry Survey on Maternal and Newborn Health): a cross-sectional study // J.Lancet, 2013, vol. 381, p. 1747-1755

51. Thaxton J.E., Nevers T.A., Sharma S. TLR-mediated preterm birth in response to pathogenic agents. Infect. Dis. Obstet. Gynecol., 2010, pii: 378472.

52. Wallace M.E., Mendola P., Chen Z. et al. Preterm Birth in the Context of Increasing Income Inequality // Maternal and child health Journal. 2015, vol. 20(1), DOI: 10.1007/s10995015-1816-9 


\title{
XÜLASə
}

\section{VAXTINDAN OVVOL DOĞULMUŞ UŞAQLARDA \\ MəRKəZI SINIR SISTEMININ PERINATAL DÖVRÜNÜN PATOLOGIYALARININ FORMALAŞMASINDA PATOGENETIK MEXANIZMLORİN ROLU}

\author{
Osədova T.A. \\ Ә. Oliyev adına Azərbaycan Dövlat Həkimlərin Təkmillaşdirmə Institutu, pediatriya kafedrasl, \\ Bakl, Azarbaycan
}

\begin{abstract}
Məqalədə perinatal dövrün patologiyalarının formalaşmasının patogenetik mexanizmləri, vaxtından əvvəl doğulmuş uşaqlarda həm hipoksik, həm də iltihabi proseslərin yaranmasında onların rolu nəzərdən keçirilir. Son illərin ədəbiyyat məlumatlarına görə vaxtından əvvəl doğulmuş uşağın baş beyni hipoksik və iltihabi proseslərdən mükəmməl müdafiə sistemi deyil. Məqalədə hestasion yaşdan asılı olaraq, vaxtından əvvəl doğulmuş uşaqların vaxtında doğulmuş uşaqlarla müqayisədə baş beyninin quruluşunun səciyyəvi xüsusiyyətləri verilmişdir. Hesab edilir ki, fetoplasentar sistemdə yaranan infeksion və qeyri-infeksion patoloji proseslər, dölün embrional inkişafına birbaşa təsir edir ki, bunun nəticəsində də patoloji prosesə daha çox baş beyin məruz qalır.

Açar sözlər: perinatal patologiya, mərkəzi sinir sistemi, vaxtından əvvəl doğuş, vaxtından əvvəl doğulmuş uşaqlar, mərkəzi sinir sisteminin hipoksik zədələnmələri.
\end{abstract}

\section{SUMMARY}

\section{THE ROLE OF PATHOGENETIC MECHANISMS IN FORMATION OF PATHOLOGY CENTRAL NEVROUS SYSTEM OF PERINATAL THE PERIOD OF THE PRIMARY CHILDREN}

\author{
Asadova T.A. \\ Azerbaijan State Advanced Training Institute for Doctors named after A. Aliyev, \\ Department of Pediatrics, Azerbaijan, Baku
}

The article deals with pathogenetic mechanisms in the formation of pathology of the perinatal period in premature infants. Their role in the emergence of both hypoxic and inflammatory processes in premature infants. According to literature data for the last few years, the brain of a premature baby is not a perfect system for protecting against the onset of hypoxic and inflammatory processes. In the article the characteristic features of the structure of the brain of premature infants are shown, depending on the gestational age, in a comparative aspect with the term infants. It is believed that the infectious and non-infectious pathological processes occurring in the fetoplacental system directly affect the embryonic development of the fetus, resulting in the pathological effect most often affected by the brain. Keywords: perinatal pathology, central nervous system, premature birth, premature infants, hypoxic lesions of the central nervous system.

Redaksiyaya daxil olub: 08.12 .2018

Çapa tövsiy olunub: 29.12.2018

Rayçi: prof. Mammadbayli A.K. 